TABLE 2 TRACE ELEMENTS IN HERBAGE FROM

SLUDGE-TREATED AND UNTREATED PLOTS

\begin{tabular}{rllllc}
\hline & $\mathrm{Cu}$ & $\mathrm{Pb}$ & $\mathrm{Ni}$ & $\mathrm{Zn}$ & $\mathrm{Cd}$ \\
Sept.86 C & 7.3 & 0.76 & 0.77 & 20 & 0.14 \\
$\mathrm{~T}$ & 8.2 & 1.1 & 1.6 & 55 & 0.23 \\
\hline
\end{tabular}

soil from the control and treated plots in 1986 is given in Table 1 . These results indicate substantial long-term contamination of the soil with respect to every element determined; contamination of top soil can persist for 15 years after a single application of sewage sludge. The effects of this contamination in this case are likely to be exacerbated by the final difference in $\mathrm{pH}$ between the soils from the control $(\mathrm{pH} \mathrm{5.8)}$ and sludge-treated (pH 5.1) plots.

The trace-element composition of the herbage grown on the control and treated areas sampled in 1986 is given in Table 2. These results indicate persistent significant enhancement of the levels of copper, lead, nickel, zinc and cadmium in herbage from the sludge-treated plot. Although none of these levels is hazardous, it is clear that there has been no significant reduction in availability of these metals over the 15 -year period. This finding is in general agreement with other reports ${ }^{3-6}$. Contamination of soils with a wide range of potentially toxic metals following application of sewage sludge is therefore virtually irreversible.

In view of the undesirability of entry of potentially toxic metals into food chains from contaminated soils, the ocean may well be the best long-term site for disposal of metal-contaminated sewage sludge. The total volume of the Earth's hydrosphere has been estimated by Park' as 1.4 $\times 10^{18}$ cubic metres. The dilution potential of this enormous mass of water is ultimately an insurance against even serious abuses.

\section{Edinburgh School of Agriculture,}

DAVID PURVES

\section{West Mains Road,}

Edinburgh EH9 3JG, UK

1. Purves, D. in Trace-element Contamination of the Environ ment 2nd edn 84-85 (Elsevier, Amsterdam, 1985)

2. Purves, D. Environ. Geochem. Hith 8, 11 (1986)

3. De Haan, F.A.M. in Waste Water Renovation and Reuse (ed. D'Itri, F.M.) 283-316 (Dekker, New York, 1977)

4. Emmerich, W.E., Lund, L.J., Page, A.L. \& Chang, A.C. J. environ. Qual. 11, 174-178(1982).

5. Berrow, M.L. \& Burridge, J.C. Symp. Chem. Heavy Metals Soils and their Avail. to Plants (Royal Society of Chemistry Agriculture Group. Rothamsted, 1986)

6. McGrath, S.P., Brooks, P.C. \& Giller, K.E. Symp. Chem Heavy metals Soils and their Avail to Plants (Royal Society of Chemistry Agriculture Group. Harpenden, 1986)

Park, P.K. in Water and Aqueous Solutions (ed. Horne, Park, P.K. in Water and Aqueou
R.A.) (Wiley, New York, 1972).

\title{
Genetic linkage in mental illness
}

SIR - The recent articles ${ }^{1-3}$ on genetic findings in mental disorders raise important issues regarding the interpretation of linkage results in complex diseases. Central to this debate is the question of what constitutes evidence for linkage in common disorders with non-mendelian transmission and phenotypic uncertainties. I would like to provide a broader perspective.

First, the lod score statistic (the logarithm of odds in favour of the linkage hypothesis) was devised primarily for rare mendelian diseases ${ }^{4}$. In the absence of prior clear evidence for major gene effects in mental disorders (segregation analysis, biochemical clues), and given the other complications discussed below, there is no theoretical foundation for designating a particular lod criterion as 'proof' of linkage (that is, a lod threshold high enough to make false-positives unlikely). But it stands to reason that the higher the lod the more likely it is that a given finding is correct. That is not to say that mendelian transmission may not exist in some subsets of mental illness - indeed, this is the basic tenet of linkage studies in psychiatry but the evidence for linkage must be scrutinized closely.

Second, because of the complexity of these conditions, linkage analysis often involves several definitions of disease and, possibly, permutations of genetic parameters and model assumptions which can be varied to maximize, and thereby inflate, the lod score (type I error). Thus, the confounding effect of testing multiple marker $\operatorname{loci}^{3}$ is but one among other encountered in multiple test models.

Third, conditions common in some mental disorders such as aetiological heterogeneity, diagnostic uncertainties and phenocopies, incomplete penetrance, misspecification of genetic parameters, assortative mating and other forms of bilineal transmission, and cohort effect, may lead to false negative linkages (type II error). False claims of non-linkage, including non-replication of positive linkage findings, are just as destructive to the field as type I errors.

What, then, is the solution? I would like to suggest some guidelines. (1) The conventional lod score approach may have to be augmented by other statistical methods such as empirical significance levels derived from the actual disease pedigrees. Further advance in linkage methodology and molecular biology techniques will be required to devise guidelines for optimal sample design in non-mendelian disorders, to unravel interaction among loci and to detect with confidence 'minor' locus effects. (2) Linkage results based on a narrowly defined phenotype with greater diagnostic reliability and presumed validity than broader disease categories may be accorded greater weight. (3) Analysis of strictly defined cases in which unaffecteds are assumed to have unknown phenotypes, thus obviating the question of incomplete penetrance. (4) Introduction of quantitative clinical and/or biological covariates which grade stability and severity of the psychiatric diagnosis. Quantification of potential diagnostic errors could enhance the use and precision of linkage analysis. (These measures could also be instrumental in sorting out homogeneous illness subsets which could be more amenable to the linkage approach.) (5) When several diagnostic schemes and model specifications are used, they should be spelled out clearly, selected before the analysis and not be allowed to "proliferate'. Some adjustments to multiple test effects have been proposed ${ }^{5.6}$. (6) Priority should be given to pedigrees with no evidence of bilineal transmission. Also, to maximize the amount of potentially useful genetic information, simulation studies of pedigree structure and disease phenotypes could be used to determine a priori the pedigrees most suitable for the linkage analysis. (7) The reliability of the psychiatric diagnosis should be checked periodically to avert diagnostic 'drift'. (8) Marker typing and diagnostic assessment should be blinded with respect to each other.

These measures could lead to more consistent linkage results. Although independent replication is the ultimate gold standard, it may not be easy to come by in the near term, primarily because of aetiological heterogeneity. In the meantime, reported linkages can be subjected to further scrutiny by diagnostic follow-up (aimed at assessing new illness onset and diagnostic stability), extension of pedigrees, reanalysis of the data using stringent diagnostic criteria, and testing new marker loci in the candidate chromosomal region to confirm and refine the putative gene location. A case in point is the reevaluation of the Amish data which has all but dashed the previously claimed linkage between bipolar affective disorders and chromosome $11 \mathrm{p} \mathrm{loci}$.

It is perhaps unavoidable that the path toward the elucidation of genetic aetiology in mental disorders will be marked by fits and starts. My proposed guidelines may render the task at hand less convoluted. Some of these issues have been discussed in detail elsewhere ${ }^{8-17}$.

Department of Psychiatry,

Columbia University,

College of Physicians and Surgeons,

New York, New York 10032, USA

1. Robertson, M. Nature 342, 222 (1989)

2. Gurling, H. Nature 344, 298 (1990).

3. Edwards, J. Nature 344, 298-299 (1990)

4. Morton, N.E. Am. J. hum. Genet. 7, 277-318 (1955).

5. Lander, E.S. \& Lincoln, S.E. Am. J. hum. Genet. 43 396-400 (1988).

6. Ott, J. Proc. natn. Acad. Sci. U.S.A. 86, 4175-4178 (1989)

Kelsoe, J.R. et al. Nature 342, 238-243 (1989)

8. Baron, M. et al. Acta psychiat. Scand. (in the press).

9. Baron, M., Endicott, J. \& Ott, J. Br. J. Psychiat. (in the press).

10. Risch, N. Genet. Epidemiol. 7, 3-16 (1990). 